\title{
Importance of Superior Rectal Artery Preservation in Videolaparoscopic Rectosigmoidectomy for Benign Disease
}

\author{
Doryane Maria dos Reis Lima ${ }^{1 *}$, João Paulo de Bortolli ${ }^{2}$, Gustavo Kurachi ${ }^{3}$ and Univaldo Etsuo Sagae ${ }^{4}$ \\ ${ }^{1}$ Coleta de dados: João Paulo de Bortolli, Brazil \\ ${ }^{2}$ Execução de pesquisa: Gustavo Kurachi e Univaldo Etsuo Sagae, Brazil \\ ${ }^{3}$ Redação de texto e análise estatística: Doryane Maria dos Reis Lima, Brazil \\ ${ }^{4}$ Professor of the Discipline of Gastroenterology, Brazil
}

Submission: March 27, 2017; Published: April 07, 2017

"Corresponding author: Doryane Maria dos Reis Lima, Coleta de dados: João Paulo de Bortolli, Univaldo Etsuo Sagae Centro Universitário, FAG Hospital São Lucas, Brazil, Tel: (45) 2101-7700; Email: doryane@gmail.com

\begin{abstract}
Objective: Demonstrate the importance of superior rectal artery preservation in videolaparoscopic rectosigmoidectomy for benign disease and determine the incidence of dehiscence.

Methods: Prospective study conducted by the colorectal surgery team at Gastroclínica Cascavel on 28 patients (mean: 45.4 years) submitted to video laparoscopic rectosigmoidectomy for benign disease between January 2010 and June 2012. The patients were treated for diverticular disease $(n=15)$ and endometriosis $(n=13)$. The surgical approach was medial, starting by ligating the inferior mesenteric vein (IMV) in most cases. Then the IMV was dissected and the superior branch of the left colic artery was ligated with a clip, preserving the inferior branch and the SRA. Only the sigmoid vessels of the area to be resected were ligated using an ultrasonic scalpel. The rectum was sectioned with a linear stapler after dissection of the mesorectum, with care taken not to injure the SRA. After verifying the integrity of the arc of Riolan, the anastomosis was performed intra-abdominally and reinforced with a double-layered suture.
\end{abstract}

Results: None of our patients developed anastomotic fistula. Two patients were reoperated in the early postoperative period for other reasons. In addition, one patient presented impotence in the late postoperative period, three patients had constipation, and one reported tenesmus for three months.

Conclusion: We demonstrated that SRA preservation during videolaparoscopic rectosigmoidectomy for benign disease possible to preserve the innervation and vascularization in the remaining colon and rectum, contributing to a lower incidence of anastomotic dehiscence.

Keywords: Colorectal surgery; Superior rectal artery; Anastomotic dehiscence

\section{Introduction}

Videolaparoscopic colorectal surgery has gained wide acceptance, especially in the treatment of benign conditions such as diverticular disease. Several techniques and modifications have been proposed to improve morbidity and mortality associated with left hemicolectomy, rectosigmoidectomy and sigmoidectomy [1]. Colorectal anastomotic dehiscence following these procedures significantly impact morbidity and mortality as well as treatment costs, especially in patients with benign conditions [2]. Ischemia or poor irrigation in the anastomosis is a major cause of dehiscence. Another complication worthy of mention, anterior rectal resection syndrome (ARRS) is characterized mainly by incontinence and/or fecal urgency, soiling, alternating bowel function and fragmented stools. Denervation of the distal colon segment is the main cause of ARRS following sigmoid resection [3-6].

The risk of dehiscence may be reduced by adopting a range of techniques (e.g. protective ostomy, mechanical stapling, double-layered suture, compression anastomosis clips, endoluminal compression anastomosis rings and bioabsorbable Seamguard ${ }^{\circledR}$ rings). One such technique, superior rectal artery (SRA) preservation, has been described for patients with proximal sigmoid and descending colon cancer with adequate lymphadenectomy [7-9], although it is inadvisable in oncological surgery as it reduces chances of satisfactory lymphadenectomy. 
SRA preservation can reduce the risk of colon denervation, favoring postoperative bowel function and avoiding ARRS $[4,5,10-13]$. The superior, middle and inferior rectum is irrigated mainly by the SRA. SRA preservation also preserves pelvic circulation and innervation, with reduced risk of functional impairment (sexual, urinary, evacuatory and fertility), but in addition to prolonging surgery, the procedure requires surgical skill and detailed knowledge of local anatomy to dissect the correct layer and ligate the sigmoid branches.

\section{Objective}

To demonstrate the importance of SRA preservation in video laparoscopic recto sigmoidectomy for benign disease and determine the incidence of dehiscence.

\section{Methods}

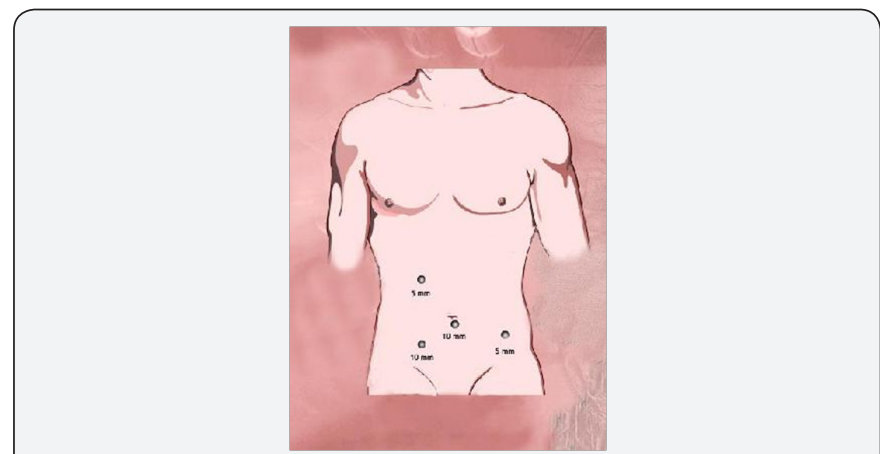

Figure 1: Position of trocars in patients treated for endometriosis.

This prospective study was conducted by the colorectal surgery team at Gastroclínica Cascavel (Paraná, Brazil) on 28 patients (23 women and 5 men) aged 28-67 years (mean: 45.4) submitted to video laparoscopic rectosigmoidectomy for benign disease between January 2010 and June 2012. The patients were treated for diverticular disease (DDC) $(n=15)$ and endometriosis (END) $(n=13)$. The sample did not include patients with malignancy or patients submitted to ostomy, laparotomy or conversion to laparotomy. Twelve hours prior to surgery, the patients were prepared with a phospho soda solution p.o. (3 bottles). Following surgery under general anesthesia, the patients were given ceftriaxone and metronidazole for 2 days (as prophylaxis), common pain killers, anti-inflammatory medication and heparin s.c. Five trocars were used in all procedures $(3 \times 5 \mathrm{~mm}$, $1 \times 10 \mathrm{~mm}, 1 \times 10-12 \mathrm{~mm})$, but the configuration was different for DDC (Figure 1) and END (Figure 2).

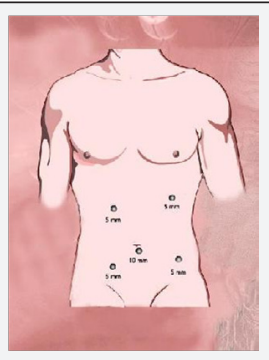

Figure 2: Position of trocars in patients treated for diverticular disease.
The surgical approach was medial, starting by ligating the inferior mesenteric vein (IMV) near the pancreas and identifying and detaching the trunk of the IMV from the descending colon and sigmoid. Then the SRA was identified as far as the branch (on the posterior rectal and mesorectal wall). Care was taken to segregate and preserve the hypogastric nerves (on the posterior wall of the image) (Figure 3). Subsequently, the SRA was skeletonized and the sigmoid branches were ligated using an ultrasonic scalpel (Figure 4). The IMV was not ligated due to the small size of the resection; thus, the vascular integrity of the SRA was preserved. The rectum was sectioned at the desired level, followed by double-stapled anastomosis performed intraabdominally with a $45 \mathrm{~mm}$ linear stapler with 1-3 cartridges and a 31 or $33 \mathrm{~mm}$ circular stapler. This was done after verifying the integrity of the arc of Riolan, which in turn was done after sectioning the colon and during the ligation of the mesocolon when the blood flow of the terminal branches of the arc and bleeding from the colon borders to be anastomosed were verified (Figure 5). An ultrasonic scalpel was used during surgery. In all patients, a double-layered suture with PDS 3.0 thread was used for reinforcement. The integrity of the anastomosis was verified with methylene blue testing and gas in sufflation, and the cavity was drained through the right iliac fossa with a Penrose drain \#3.
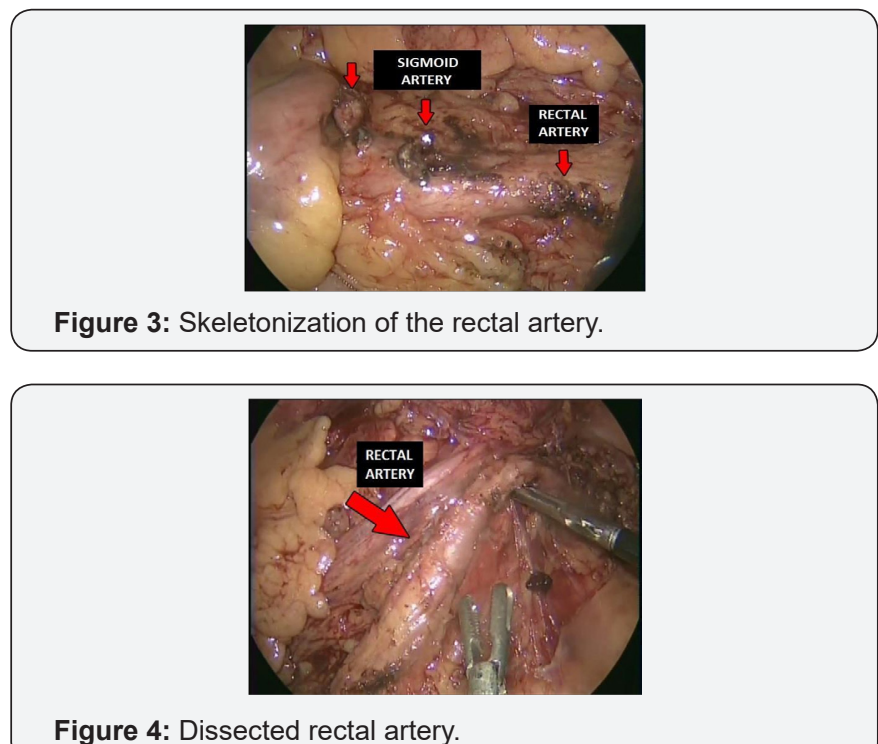

Figure 4: Dissected rectal artery.

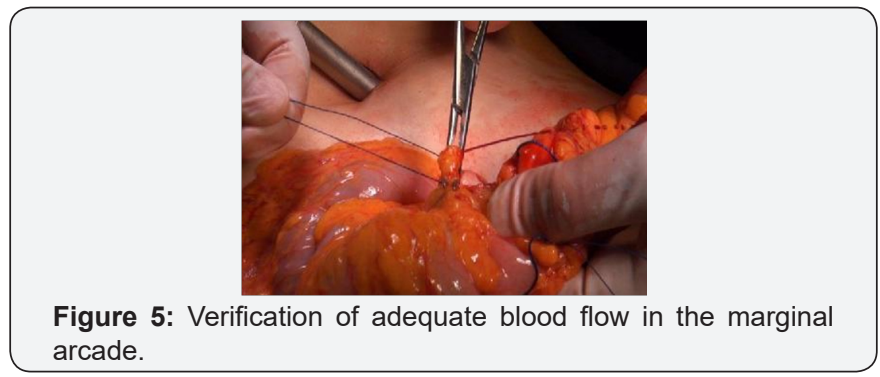

Results

Surgery lasted $136.25 \mathrm{~min}$ on the average, with an estimated blood loss of $\sim 20 \mathrm{~mL}$ ( 3 gauzes). Liquid diet was introduced 24 hours after the procedure and gradually changed to solid, 
depending on acceptance. The mean time of hospitalization was 4 days (range: $3-7$ ) and the mean follow-up time was 30 months. The transoperative complication rate was $3.5 \%$. In one patient the stapling of the anastomosis failed (the circular stapler was applied to the anterior quadrant), but this was immediately corrected with a manual suture using vicryl thread size 3.0. Two patients displayed paralytic ileus: one improved with clinical treatment, the other was reoperated due to a pelvic abscess without dehiscence of the anastomosis. Another early complication, enteric liquid in the Penrose drain due to accidental punctiform perforation of the small bowel with a Veress needle, required reoperation on the third postoperative day. In addition, one patient presented impotence in the late postoperative period, three patients experienced a change in bowel habit (constipation), and one complained of tenesmus for three months.

\section{Discussion}

Dehiscence or fistula of the anastomosis is a postoperative complication with severe implications for treatment, especially in patients with benign conditions such as END and DDC. In the literature, the incidence of dehiscence is $8-38 \%$ [14-16]. Dehiscence is associated with increased morbidity, mortality, time and cost of hospitalization, in addition to higher rates of reoperation, occasionally requiring stoma formation. Risk factors for dehiscence of colorectal anastomosis include comorbidities (e.g. hypertension, diabetes, nephropathy, pneumopathy), neoadjuvant therapy (chemo and/or radiotherapy) [17-21] and the surgical technique used to make the anastomosis [22-24].

ARRS appears to be associated with descending colon denervation and sphincter dysfunction caused by hypogastric plexus lesions during rectal mobilization or direct lesions during the introduction of the circular stapler $[3,4,25,26]$. Such lesions have been reported with up to $90 \%$ frequency after colon and distal rectal resection $[4,10,26]$.

The risk of dehiscence and related complications may be reduced by adopting any of several strategies, including SRA preservation. The superior, middle and inferior rectum is irrigated mainly by the SRA. By maintaining irrigation, SRA preservation significantly protects the integrity of low anastomoses in benign disease. In addition, pelvic innervation is preserved, minimizing the risk of sexual, urinary and evacuatory dysfunction. The preservation of the SRA near the colon wall also reduces the risk of colon denervation, favoring postoperative bowel function and potentially avoiding ARRS [4,13].

In our series of patients, as a result of the extensive experience of the surgical team, dissection and ligation of the sigmoid branches were achieved successfully and the SRA was preserved. The duration of surgery matched that reported by Bergamaschi et al [27], but was shorter than that of Lehmann et al [2]. The rate of dehiscence and impotence $(0.035 \%$ each) was lower in our series than in any published so far. The rates of the remaining complications, including constipation and tenesmus, were similar to those reported in the literature [2,27]. According to some authors, SRA preservation is associated with longer surgery and increased transoperative blood loss; however, in our study blood loss was similar to that reported for surgery without SRA preservation [2].

The low rate of dehiscence may be attributed to surgical skill or to the use of double-layered suture to reinforce the anastomosis. On the other hand, failure to evaluate the physiology of the pelvic floor at baseline and assign a functional score to each patient made it impossible to make inferences regarding the preservation of the innervation of the pelvic floor.

\section{Conclusion}

In this study we demonstrated that SRA preservation in video laparoscopic rectosigmoidectomy for benign disease (such as DDC and END) possible to preserve the innervation and vascularization in the remaining colon and rectum, contributing to a lower incidence of anastomotic dehiscence.

\section{Conflicts of Interest}

None of the authors has conflict of interest.

\section{References}

1. Masoni L, Mari FS, Nigri G, Favi F, Gasparrini M, et al. (2012) Preservation of the inferior mesenteric artery via laparoscopic sigmoid colectomy performed for diverticular disease: real benefit or technical challenge: a randomized controlled clinical trial. Surg Endosc 27(1): 199-206.

2. Lehmann RK, Brounts LR, Johnson EK, Rizzo JA, Steele SR (2011) Does sacrifice of the inferior mesenteric artery or superior rectal artery affect anastomotic leak following sigmoidectomy for diverticulitis? A retrospective review. Am J Surg 201(5): 623-627.

3. Adachi Y, Kakisako K, Sato K, Shiraishi N, Miyahara M, et al. (2000) Factors influencing bowel function after low anterior resection and sigmoid colectomy. Hepatogastroenterology 47(31): 155-158.

4. Dobrowolski S, Hać S, Kobiela J, Sledziński Z (2009) Should we preserve the inferior mesenteric artery during sigmoid colectomy? Neurogastroenterol Motil 21(12): 1288-e123.

5. Rao GN, Drew PJ, Lee PW, Monson JR, Duthie GS (1996) Anterior resection syndrome is secondary to sympathetic denervation. Int Colorectal Dis 11(5): 250-258.

6. Iizuka I, Koda K, Seike K, Shimizu K, Takami Y, et al. (2004) Defecatory malfunction caused by motility disorder of the neorectum after anterior resection for rectal cancer. Am J Surg Aug 188(2): 176-180.

7. Kobayashi M, Okamoto K, Namikawa T, Okabayashi T, Sakamoto J, et al (2007) Laparoscopic D3 lymph node dissection with preservation of the superior rectal artery for the treatment of proximal sigmoid and descending colon cancer. J Laparoendosc Adv Surg Tech A 17(4): 461466.

8. Sekimoto M, Takemasa I, Mizushima T, Ikeda M, Yamamoto H, et al. (2011) Laparoscopic lymph node dissection around the inferior mesenteric arterywith preservation of the left colic artery. Surg Endosc 25(3): 861-866.

9. Wu JH, Rong ZX, Zhu DJ, Chen XW, Ren BJ (2009) Laparoscopic anterior resection of rectal carcinoma with preservation of the left colonic artery. Nan Fang Yi Ke Da Xue Xue Bao 29(6): 1249-1250. 
10. Ho YH, Low D, Goh HS (1996) Bowel function survey after segmental colorectal resections. Dis Colon Rectum 39(3): 307-310.

11. Lee WY, Takahashi T, Pappas T, Mantyh CR, Ludwig KA (2008) Surgical autonomic denervation results in altered colonic motility: an explanation for low anterior resection syndrome? Surgery Jun 143(6): 778-83.

12. Horgan PG, O'Connell PR, Shinkwin CA, Kirwan WO (1989) Effect of anterior resection on anal sphincter function. Br J Surg 76(8): 783-786.

13. Koda K, Saito N, Seike K, Shimizu K, Kosugi C, et al. (2005) Denervation of the neorectum as a potential cause of defecatory disorder following low anterior resection for rectal cancer. Dis Colon Rectum 48(2): 210217.

14. Schlinkert RT, Beart RW, Wolff BG, Pemberton JH (1985) Anterior resection for complete rectal prolapse. Dis Colon Rectum 28(6): 409412.

15. Luukkonen P, Mikkonen U, Järvinen H (1992) Abdominal rectopexy with sigmoidectomy versus rectopexy alone for rectal prolapse: A prospective randomized study. Int J Colorectal Dis Dec 7(4): 219-222.

16. McKee RF, Lauder JC, Poon FW, Aitchison MA, Finlay IG (1992) A prospective randomized studyof abdominal rectopexy with and without sigmoidectomy in rectal prolapse. Surg Gynecol Obstet 174(2): 145-148.

17. Khan AA, Wheeler JM, Cunningham C, George B, Kettlewell M, et al. (2008) The management and outcome of anastomotic leaks in colorectal surgery. Colorectal Dis 10(6): 587-592.

18. Moran BJ, Heald RJ (2001) Risk factors for, and management of anastomotic leakage in rectal surgery. Colorectal Dis 3(2): 135-137.

19. Tang CL, Seow-Choen F (2005) Digital rectal examination compares favourably with conventional water-soluble contrast enema in the assessment of anastomotic healing after low rectal excision: a cohort study. Int J Colorectal Dis 20(3): 262-266.

20. Choi HK, Law WL, Ho JW (2006) Leakage after resection and intraperitoneal anastomosis for colorectal malignancy: analysis of risk factors. Dis Colon Rectum 49(11): 1719-1725.

21. Konishi T, Watanabe T, Kishimoto J, Nagawa H (2006) Risk factors for anastomotic leakage after surgery for colorectal cancer: results of prospective surveillance. J Am Coll Surg 202(3): 439-444.

22. Nesbakken A, Nygaard K, Lunde OC, Blücher J, Gjertsen Ø, et al. (2005) Anastomotic leak following mesorectal excision for rectal cancer: true incidence and diagnostic challenges. Colorectal Dis 7(6): 576-81.

23. Matthiessen P, Hallböök O, Andersson M, Rutegård J, Sjödahl R (2004) Risk factors for anastomotic leakage after anterior resection of the rectum. Colorectal Dis 6(6): 462-469.

24. Walker KG, Bell SW, Rickard MJ, Mehanna D, Dent OF, et al. (2004) Anastomotic leakage is predictive of diminished survival after potentially curative resection for colorectal cancer. Ann Surg 240(2): 255-259.

25. Sato K, Inomata M, Kakisako K, Shiraishi N, Adachi Y, et al. (2003) Surgical technique influences bowel function after low anterior resection and sigmoid colectomy. Hepatogastroenterology 50(53): 1381-1384.

26. Desnoo L, Faithfull S (2006) A qualitative study of anterior resection syndrome: the experiences of cancer survivors who have undergone resection surgery. Eur J Cancer Care (Engl) 15(3): 244-251.

27. Bergamaschi R, Lovvik K, Marvik R (2003) Does sacrifice of the inferior mesenteric artery or superior rectal artery affect anastomotic leak following sigmoidectomy for diverticulitis? A retrospective review. Am J Surg 13(6): 374-376.

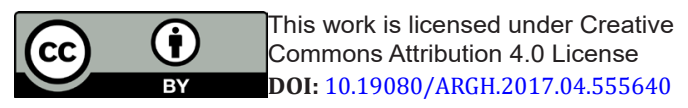

\begin{tabular}{|l|}
\hline \multicolumn{1}{|c|}{ Your next submission with JuniperPublishers } \\
will reach you the below assets \\
- Quality Editorial service \\
- Swift Peer Review \\
- Reprints availability \\
- E-prints Service \\
- Manuscript Podcast for convenient understanding \\
- Global attainment for your research \\
- Manuscript accessibility in different formats \\
( Pdf, E-pub, Full Text, audio) \\
- Unceasing customer service \\
Track the below URL for one-step submission \\
https://juniperpublishers.com/online-submission.php \\
\hline
\end{tabular}

